Ethiopian Journal of Environmental Studies \& Management 8(3): 264 - 271, 2015.

ISSN:1998-0507

doi: http://dx.doi.org/10.4314/ejesm.v8i3.3

Submitted: January 09, 2015

Accepted: March 23, 2015

\title{
SPATIAL ANALYSIS OF HEALTH FACILITIES IN SULEJA, NIGER STATE, NIGERIA
}

OWOYELE, G.S., AJOBIEWE, T.O., *IDOWU, 0.0., SHUAIBU S.I. AND MARTINS, V.I.

Department of Urban and Regional Planning

Federal University of Technology Minna, Niger State, Nigeria

\begin{abstract}
Health undoubtedly is a prerequisite for global liveability of man. Despite government policies on the provision and delivery of healthcare to all, the spatial distribution of such health facilities are subject to a number of social and commercial influences that do not take into account the healthcare needs of the population. The objective of this study was to map out the location of health facilities in Suleja, Niger State. The locations of all hospitals and clinics in the study area were identified and mapped using a combination of spatial GIS tools. The locational quotient was utilised to visualise spatial distributions and degree of concentration of all thirty-seven (37) identified health facilities. Nearest Neighbourhood Analysis (NNA) was used to establish the distribution pattern of hospitals and clinics in the study area. Hospitals showed evidence of dispersed distribution with a z-score of 5.63 implying a significant level of accessibility, while the pattern of clinic location appears to indicate an insignificant level of accessibility with a z-score of 0.43. The research proffer recommendations considering healthcare needs of the population provision for future health facilities and frequent assessment of existing health facilities by concerned health agencies/ministries.
\end{abstract}

Key Word: Distribution, Health facility, Planning location, Facility.

\section{Introduction}

The term health goes beyond absence of infirmity (Owoyele 2014). Agbola (2008) has noted and explained that health encompasses physical and psycho-social well-being, not simply the absence of disease, with many factors influences health and well being. However, the academic literature on the assessment of health facilities has increased considerably in the nineties. According to Premasudha (2010) stated that health is an absolute physical, mental, and psychological state which reflects the general condition of the body or mind, especially in terms of the presence or absence of disease or infirmity. Therefore good health is regarded as a fundamental necessity of any community because the health of a people has a direct relationship with their productive capacity and labour efficiency.

For instance in Nigeria today, the unplanned and chaotic distribution of health facilities has been on the radar of national debates, therefore planning the location of health facilities as well as the travel distance to access health care services has been a major concern to urban planners over the years. Similarly, accessibility to health facilities for an individual in spatial perspective and the physical accessibility of a household member to health care facilities are of considerable importance, but it is however constrained by distance (Aregbeyan, 1992).

*Corresponding Author: Idowu, O.O.

Email: olu.idowu@ futminna.edu.ng 
Following the increase in population, rapid rural-urban migration and urbanization, faced with massive problems of ill-health, with dissatisfaction with the state of health facilities in Nigeria has centred on its uneven spatial distribution and limited accessibility to them. This trend is as a result of the haphazard location of the available health facilities where a great percentage of the populace have no access to them.

The use of Geographic Information System (GIS) a computer based program has allowed researchers to address the geographical component to access healthcare via spatial statistics (Sanders, 2006). Similarly, Mitchell (2005) pointed out that spatial statistics involves the use of maps to incorporate analysis of feature locations and spatial relationships alongside tables of attribute values. However, the concept of spatial analysis involves the use of inferential statistics and randomisation of null hypothesis. In an urban environment, hospital/clinic accessibility could be influenced by their geographic and social features. Therefore, measuring geographic accessibility to health facilities using GIS allows a juxtaposition of such features (geographic and social) against various outcomes. Shaping health facilities to be different, more equitable and effective in new ways is borne out of the need to develop an object oriented data representation of health services in Nigerian urban centres.

The importance of the use of GIS in analysing health facilities on space cannot be over emphasized as it encompasses the design, development and utilisation of webbased tools for the description of health situations, epidemiological analyses and public management. Premasudha (2010) presented areas where GIS can be used for spatial analysis of health facilities like spatial description of health events, public health surveillance, health pattern and situation analysis, accessibility to health service and planning and programming of health services and facilities.

This study aimed at analyzing the spatial location of health facilities in Suleja, Niger State, Nigeria. In a bid to achieve the aim of this research, the objectives of this paper, therefore are, an inventory of existing health facilities in the study area as well as mapping out the location of existing health facilities in the study area. The scope of this research however covers the existing government owned and privately owned hospitals and clinics in ten (10) selected districts within the study area. These districts are; Bagama, Hashimi, Kurmin Sarki, Magajiya, Maje, Madalla, Wambai, Kabula, Rafin Sanyi and Kwamba,

\section{Study Area}

The study was conducted in Suleja, Niger State, Suleja Local Government was established by the Local Government reform of 1976 from the defunct Abuja native authority. The area lies between latitude $7^{\circ}$ $31^{\prime} \mathrm{N}$ and longitude $7^{\circ} 58^{\prime} \mathrm{E}$. It shares an immediate boundary with Gurara and Tafa in Niger state and Gwagalada in FCT. Suleja is about 20km North of Abuja the Federal Capital of Nigeria and about 100km North East of Minna the Capital of Niger State, the Local Government covers a land area of 153.4 Sq.km(Aminu, et al., 2013). The 2006 provisional population census results showed that Suleja Local Government Area has an estimated population of 216,578 people with males recording 112,672, females 103,906 and a population density of $1,412 \mathrm{~km}^{2}$ (Niger State Facts and Figures, 2011). 


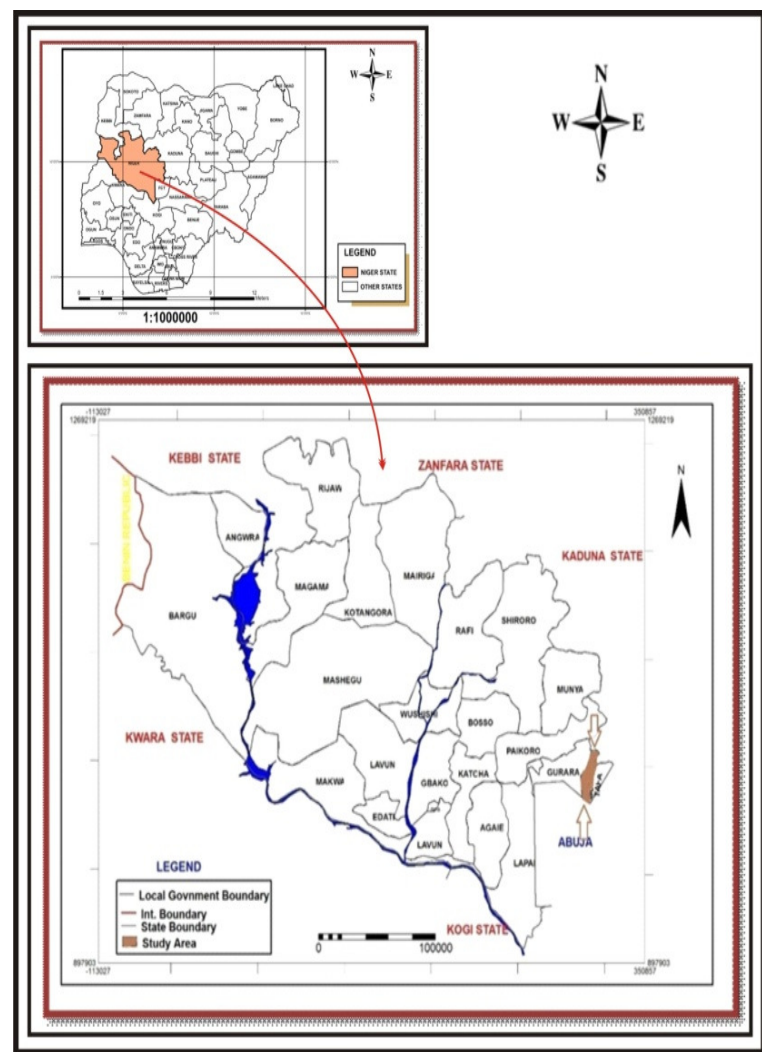

Figure 1: Map of Niger State

\section{Methodology}

For the purpose of this study, a structured questionnaire was designed and distributed in order to obtain specific information from the management of all existing hospitals and clinics within the Ten (10) districts of the study area. Hand held GPS, Meter Tape, and Goggle earth online mapping software were also used for data gathering. In addition, other analytical methods in planning were used for data analysis, such as; Locational Quotient: To analyse the degree of concentration of hospitals and clinics in each district of the study area.

The formula for LQ as presented below is; $L Q=\frac{S i / S}{N i / N}$

Where; $\mathrm{Si}=$ the number of hospitals and clinics in each district

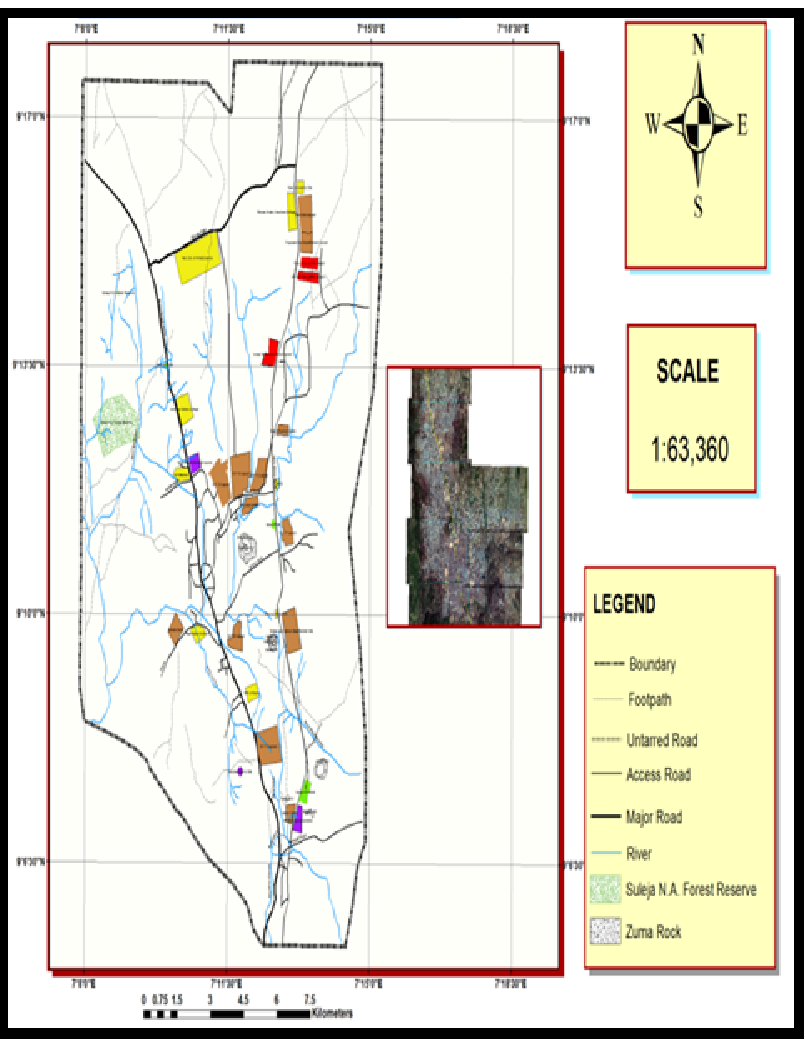

Figure 2: Map of Suleja and Environs;

$\mathrm{S}=$ the total number of health facilities (hospitals and clinics) in all the ten selected districts.

$\mathrm{Ni}=$ population of each district/ward

$\mathrm{N}=$ population of all the districts.

\section{Nearest Neighbourhood Analysis} (NNA): This inferential statistical tool was used to establish the distribution pattern of hospitals and clinics in the study area. Presentations of analyzed data are displayed with simple tables, illustrative charts and maps.

\section{Results}

Table 1 shows detailed analysis of the location and distribution of hospitals and clinics in selected districts of Suleja, Niger State, Nigeria. 
Table 1: Location of Hospitals/Clinics, Area Coverage, Bed Capacity and Co-ordinates.

\begin{tabular}{|c|c|c|c|c|c|c|}
\hline \multirow[t]{2}{*}{$\mathrm{S} / \mathrm{N}$} & \multirow[t]{2}{*}{ Hospital/Clinic } & \multirow[t]{2}{*}{ Location } & \multirow[t]{2}{*}{ Area $\left(\mathrm{m}^{2}\right)$} & \multirow{2}{*}{$\begin{array}{l}\text { Bed } \\
\text { Capacity }\end{array}$} & \multicolumn{2}{|c|}{ Co-ordinates } \\
\hline & & & & & Eastings & Nothings \\
\hline 1 & Suzan Hospital & Bagama & 363 & 20 & 0300638 & 1015612 \\
\hline 2 & $\begin{array}{l}\text { Late Yakubu Adamu Aso Memorial } \\
\text { Clinic }\end{array}$ & Magajiya & 60 & 3 & 0299725 & 1014505 \\
\hline 3 & Citizen Hospital & Kabula & 321 & 15 & 0300338 & 1016453 \\
\hline 4 & Dije Bala Public Health Clinic & Wambai & 163 & 7 & 0299932 & 1014655 \\
\hline 5 & As Sayafat Clinic & Kurmin Sarki & 135 & 8 & 0299391 & 1016019 \\
\hline 6 & Royal Hospital & Kurmin Sarki & 193 & 10 & 0299581 & 1015982 \\
\hline 7 & Suleja Hospital & Hashimi & 135 & 12 & 0299655 & 1015810 \\
\hline 8 & Spring Valley Hospital & Kabula & 158.7 & 21 & 0300598 & 1016823 \\
\hline 9 & Liberty Hospital & Hashimi & 154 & 12 & 0299934 & 1016186 \\
\hline 10 & Solace Hospital & Hashimi & 158 & 9 & 0299537 & 1015383 \\
\hline 11 & Base Medical Hospital & Kabula & 323 & 18 & 0300552 & 1016731 \\
\hline 12 & Maraba Hospital & Hashimi & 440 & 20 & 0299980 & 1016804 \\
\hline 13 & Delight Hospital & Kabula & 252 & 10 & 0300767 & 1016380 \\
\hline 14 & Talba Clinic low cost G.R.A. & Kabula & 144 & 6 & 0300457 & 1016245 \\
\hline 15 & Samaritan Hospital & Hashimi & 156 & 10 & 0299998 & 1017113 \\
\hline 16 & Salasi Clinic & Maje & 116 & 9 & 0299539 & 1017167 \\
\hline 17 & Denyion Hospital & Madalla & 185 & 12 & 0303354 & 1008276 \\
\hline 18 & Lucas Maternity Hospital & Madalla & 321 & 22 & 0303991 & 1007417 \\
\hline 19 & Madalla Medical Centre & Madalla & 182 & 20 & 0304704 & 1007779 \\
\hline 20 & Divine Clinic & Madalla & 105 & 4 & 0303416 & 1007628 \\
\hline 21 & Late Sarkin Pawa Health Clinic & Wambai & 594 & 11 & 0300053 & 1015172 \\
\hline 22 & Living Space Nature Cure Hospital & Kwamba & 96 & - & 0220087 & 1055023 \\
\hline 23 & $\begin{array}{l}\text { Salihu Madalla Comprehensive } \\
\text { Health Clinic }\end{array}$ & Madalla & 360 & 15 & 0303870 & 1006876 \\
\hline 24 & Mayor Royal Clinic & Madalla & 86 & 5 & 0303922 & 1007482 \\
\hline 25 & King Salem Hospital & Rafin Sanyi & 226 & 11 & 0300592 & 1012808 \\
\hline 26 & Diamond Hospital & Bagama & 120 & 12 & 0300561 & 1015070 \\
\hline 27 & Salam Hospital & Hashimi & 98 & 10 & 0299814 & 1015326 \\
\hline 28 & General Hospital & Kurmin Sarki & 19,308 & 147 & 0299799 & 1016448 \\
\hline 29 & Fary Group of Clinic & Kabula & 312 & 18 & 0300376 & 1016853 \\
\hline 30 & Gaskiya Hospital & Hashimi & 288 & 24 & 0300038 & 1015816 \\
\hline 31 & Optima Family Medical Centre & Kurmin Sarki & 216 & 11 & 0299536 & 1017158 \\
\hline 32 & Doctor Charles Hospital & Rafin Sanyi & 209 & 12 & 0301598 & 1011813 \\
\hline 33 & Goshen Hospital & Rafin Sanyi & 277 & 15 & 300776.4 & 1014142 \\
\hline 34 & Zuma Hospital & Madalla & 310 & 18 & 303286 & 1008824 \\
\hline 35 & Igechi Clinic & Madalla & 110 & 5 & 303305 & 1008044 \\
\hline 36 & Alheri Clinic & Madalla & 136 & 7 & 303916 & 1008182 \\
\hline 37 & Gaza Clinic & Madalla & 129 & - & 303640 & 1008487 \\
\hline
\end{tabular}

Table 2: Distribution of Health Facilities

\begin{tabular}{lll}
\hline District & Frequency & Percentage (\%) \\
\hline Bagama & 2 & 5.4 \\
Hashimi & 7 & 18.9 \\
Kabula & 6 & 16.2 \\
Kwamba & 1 & 2.7 \\
Kurmin Sarki & 4 & 10.8 \\
Madalla & 10 & 27 \\
Magajiya & 1 & 2.7 \\
Maje & 1 & 2.7 \\
Rafin Sanyi & 3 & 8.1 \\
Wambai & 2 & 5.4 \\
\hline Total & 37 & 100 \\
\hline
\end{tabular}


Out of the 37 health facilities (hospitals and clinics) observed in the selected districts of the study area as shown in Table 2, ten of them are located in Madalla district, seven in Kabula district, while Magajiya, Maje, and Kwamba, districts one health facility each

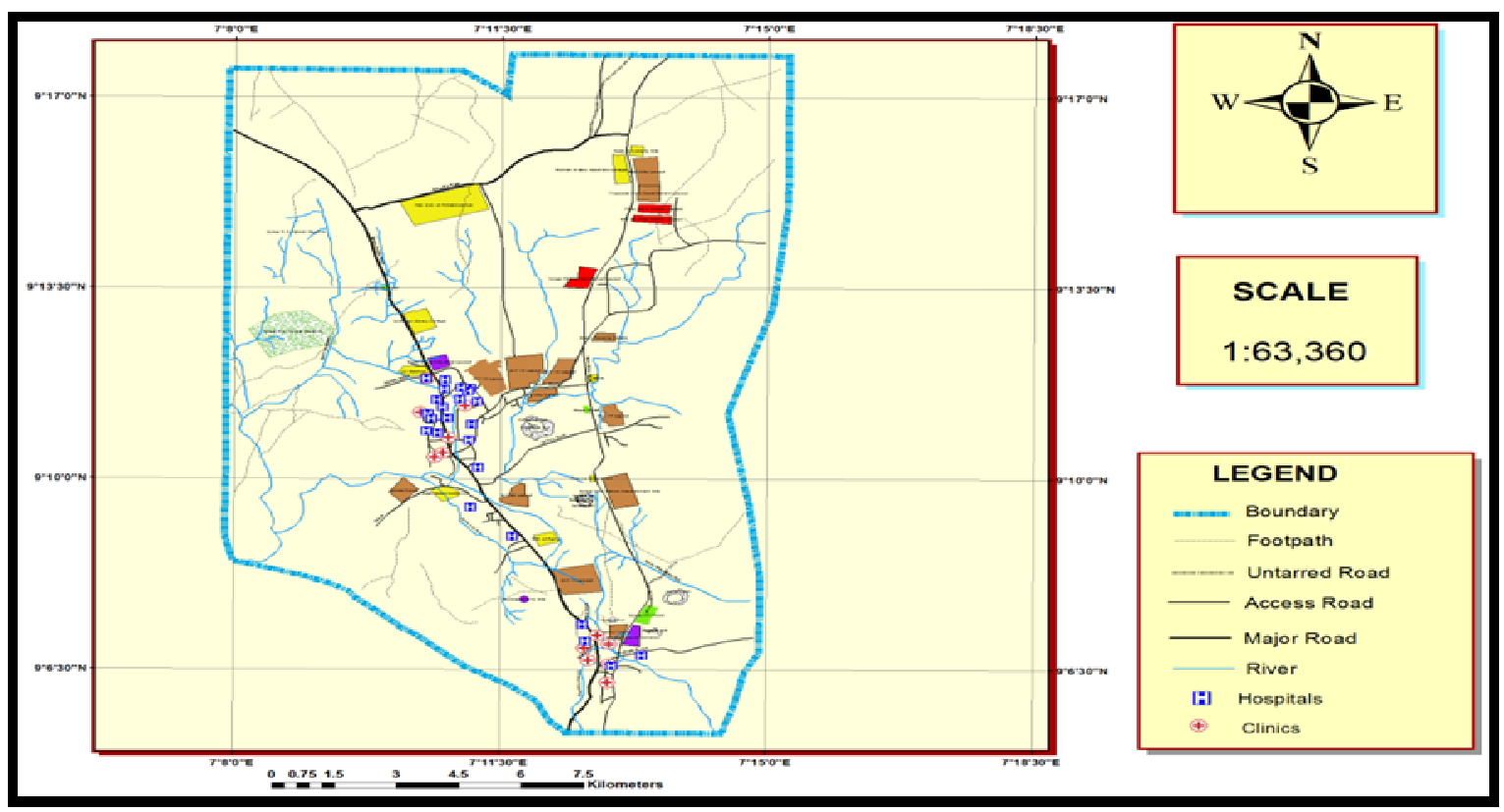

Figure 3: Location Map of health facilities in Suleja

Table 3: Locational Quotient of Hospitals and Clinics

\begin{tabular}{lllll}
\hline S/N & District & Population & Health Facility & Location Quotient \\
\hline 1 & Bagama & 27,009 & 2 & 0.51 \\
2 & Hashimi & 24,072 & 7 & 1.99 \\
3 & Kabula & 25,088 & 6 & 1.64 \\
4 & Kurmin Sarki & 27,449 & 4 & 1.04 \\
5 & Madalla & 30,643 & 10 & 2.25 \\
6 & Magajiya & 26,174 & 1 & 0.26 \\
7 & Maje (Maje and Kwamba) & 29,038 & 2 & 0.47 \\
8 & Rafin Sanyi & 32,242 & 3 & 0.64 \\
9 & Wambai & 31,947 & 2 & 0.43 \\
\hline & Total & 253,662 & 37 &
\end{tabular}

A locational quotient value of less than 1 signifies a condition of having less than a fair share of a facility, a value of 1 means having a fair share of a facility while a value greater than 1 indicates that there is more than a fair share distribution of the facilities understudied. Hence, Bagama, Magajiya, Maje, Kwamba, Rafin Sanyi and Wambai districts had less than a fair share distribution of health facilities in the study area. Nevertheless, Hashimi, Kabula, Kurmin Sarki and Madalla districts had more than a fair share distribution of hospitals and clinics in the study area.

Table 4: Ownerships of Hospitals and Clinics

\begin{tabular}{lll}
\hline Ownership & Frequency & Percent $(\%)$ \\
\hline Government Owned & 7 & 18.92 \\
Private Owned & 30 & 81.08 \\
Total & 37 & 100.00 \\
\hline
\end{tabular}


The analysis revealed that there are seven government owned hospital/Clinics. One of them is the General Hospital Suleja established in 1969 while other six serves as clinic distributed in the area. Also, there are thirty (30) private hospitals/Clinics distributed across the districts of the study area.

Table 5: Additional Facilities

\begin{tabular}{lll}
\hline Additional Facility & Frequency & Percent \\
\hline Parking Facility & 20 & 64.5 \\
Ambulance Facility & 13 & 41.9 \\
\hline
\end{tabular}

The survey in Table 5 also shows that more than half of the health facilities $(64.5 \%)$ have parking facilities and at least one ambulance facility. However, none of the clinics have ambulance facilities.

Nearest Neighbourhood Analysis (NNA)

For this study NNA was used to determine the level of randomness and accessibility to the health facilities in Suleja. From the analysis, the following was found about hospital locations;

Observed mean distance $=3988$;

Expected mean distance $=2511$

Nearest Neighbour ratio $=1.58$;

Z-score $=5.63$

Standard derivation P-Value $=0.00$;

Significant level $=0.01$;

Critical value $=>2.58$.

Given the z-score of 5.63, there is less than $1 \%$ likelihood that the dispersed pattern of hospital location and distribution in the study area could be the result of random chance. An output of 1.58 was found, an indication of strong randomness, because it is below the Z-score table value of 5.63. Therefore indicates a significant accessibility status.

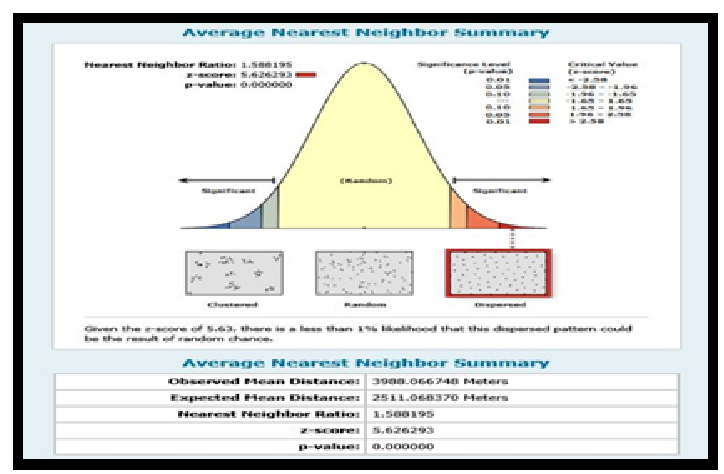

Figure 4: Nearest Neighbourhood Analysis for Hospitals in Suleja.

From the analysis, the following was found about clinic locations;

Observed mean distance $=598.59$;

Expected mean distance $=562.17$

Nearest Neighbour ratio $=1.06$;

Z-score $=0.43$

Standard derivation P-Value $=0.66$;

Significant level $=0$

Critical value $=-1.65-1.65$.

Given the z-score of 0.43 , the pattern does not appear to be significantly different than random. An output of 1.06 was found, an indication of weak randomness, because it exceeds the Z-score table value of 0.43 , which is an indication of insignificant accessibility.

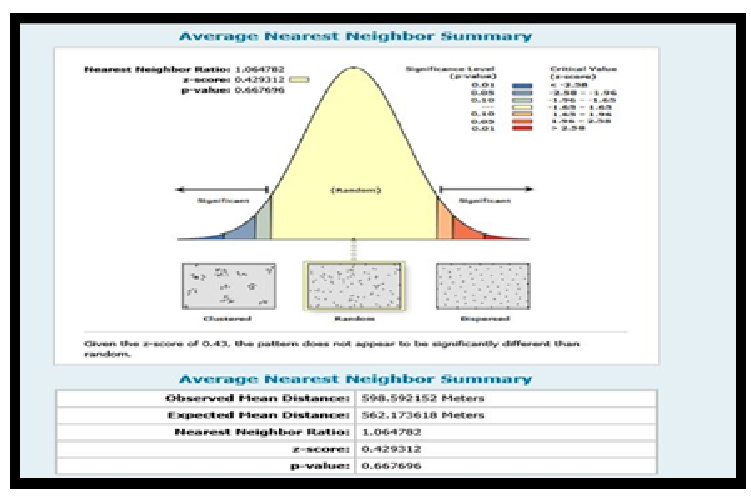

Figure 5: Nearest Neighbourhood Analysis for Clinics in Suleja. 


\section{Discussion}

From the analysis displayed with tables, figures and maps, the following observations were made regarding hospitals and clinics in Suleja;

\section{Distribution}

Table 1 and 2 shows the distribution of the health care facility, which by implication there are districts that are more in numbers of health facility than others; Madalla (ten), Hashimi (seven), Kabula (six) and Kurmi Saki (four) which considered marginal. Districts like Kwamba, Magajiya and Maje are distributed with each health care facility. The locations of the district considerably influence the distribution of the facility, as most of the district with facility from four and more are within the core of the town, while the latter are within the suburb of the town.

\section{Location}

The report identified and justified two major distribution of health care facility in Suleja. From the location quotient value, there are district with less fair share of the facility: Bagama, Magajiya, Maje, Kwamba, Rafin Sanyi and Wambai. The district that has more than the fair share include Hashimi, Kabula, Kurmi Saki and Madalla. Accessibility

The General hospital in Kurmin Sarki is accessed by a major road (Minna-Suleja) 12 metre road while other health facilities are accessible by Suleja township roads of various sizes, some of which are tarred with roadside drainage while others are earth roads.

\section{Recommendations}

The uneven spatial distribution of health facilities in Suleja is a huge challenge that the government of Niger state has to address in order to achieve equitable healthcare accessibility. In line with the above findings, the following recommendations are made:

- While investing in healthcare delivery, it is important that the stakeholders involved do that by planning and making provisions where a known demand for the supposed healthcare service is said to exist. Also project identification, evaluation and execution of health facilities should be based on the needs of the population. In essence political influences on facility location in general should be minimized.

- An inventory of existing health facilities should be conducted regularly by the relevant health agencies/ministries such that facilities in need of expansion in terms of physical structure, bed capacity, parking facility, ambulance facility, and number of health personnel to mention but a few are immediately given the needed attention and addressed thereafter.

- As contained in the vision 3:2020 of Niger state, an implementation of policies contained in the document should be expressly pursued by the state government. This will make it possible to plan for development of districts disadvantaged in terms of healthcare delivery, therefore reducing the discrepancy in the development of the local government area.

- In addition it is very important that the Government of Niger State should consider upgrading and renovating General Hospital Suleja established in 1969. The hospital environment, its buildings, ambulances as well as their health personnel has to be given considerable interest when carrying out the upgrading and renovation.

\section{Conclusion}

Findings gathered from the research shows that there are inequalities in the spatial location/distribution of health facilities (hospitals and clinics) within the study area i.e. more than half of the sampled districts have less than a fair share distribution of hospitals/clinics within the 
study area, which basically implies that some districts are having inadequate healthcare delivery, while others have excess clustering around few neighbourhoods.

Undoubtedly, government at all levels has an obligation to meet the welfare of its citizens; therefore, the provision of health facilities in areas where they are lacking or inadequate will be an attempt to fulfil such obligation. In meeting such obligation nonetheless, it is important to note that facilities should be located with utmost regard to the distribution and accessibility of these facilities such that equity and equitability is achieved.

Conclusively, future location of health facilities can be vigorously pursued by using GIS tools. Similarly, government and private owned health establishments must live up to expectation by ensuring better healthcare delivery in all its facets, aspects and ramifications.

\section{References}

Agbola, S.B. (2008). Conceptualizing Health and Environment, Ibadan: Ibadan University Press.

Aminu, Z., Yakubu, M., Mohammed, A.A. and Niranjan, K. (2013). 'Impact of Land Use on Soil Quality in Suleja, Niger State. Indian Journal of Science, 2(2):1-7.

Aregbeyan, J.B.O. (1992). 'Healthcare Service Utilization in Nigeria Rural Communities, A focus on Otuo
Community and Environs in Edo state.' NISER Monographyseries, Ibadan.

Mitchell, A. (2005). 'The ESRI guide to GIS analysis': Spatial measurements \& statistics Vol. 2. Redlands, California: ESRI Press.

Niger State Facts and Figures (2011). pp2230.

Owoyele, G.S. (2014). Assessment of the Relationship between Neighbourhood Quality and Human Health in Minna, Niger State. An unpublished PhD Thesis submitted to the Dept. of Urban and Regional Planning Federal University of Technology, Minna.

Premasudha, B.G. (2010). 'Visualization and Spatial Analysis of Healthcare Services of Tumkur City. An Unpublished PhD Thesis submitted to Computer Applications Dept. Dr M.G.R Educational and Research Institute University.

Sanders, L.J. (2006). 'A Spatial Analysis of the Geographic Distribution of Musculoskeletal and General Practice Healthcare Clinics in Auckland, New Zealand.' An Unpublished Master of osteopathy thesis submitted to Unitec. Institute of Technology, New Zealand.

World Health Organisation (1978). 'Primary Health care. Report of the International Conference at Alma Alta, World Health Organisation, Geneva, Switzerland. 